\title{
BIOMETRIA DE FRUTOS E SEMENTES E EMERGÊNCIA DE PLÂNTULAS DE DUAS ESPÉCIES FRUTÍFERAS DO GÊNERO Campomanesia ${ }^{1}$
}

\author{
MICHELE CAMARGO DE OLIVEIRA², DENISE GARCIA DE SANTANA ${ }^{3}$, \\ CARLOS MACHADO DOS SANTOS ${ }^{4}$
}

RESUMO - As espécies Campomanesia adamantium e Campomanesia pubescens são morfologicamente semelhantes, ocorrem em ambientes comuns do Bioma Cerrado, por isso são difíceis de serem separadas e identificadas. Os objetivos foram analisar dados biométricos de frutos e sementes de $C$. adamantium e de $C$. pubescens, além do processo de emergência das plântulas, para fins de comparações entre as espécies. Em novembro de 2007, de 50 frutos de cada espécie, foram realizadas medidas do comprimento transversal (mm) e longitudinal $(\mathrm{mm})$ dos frutos e das sementes, massa da matéria fresca dos frutos $(\mathrm{g})$, número de lóculos por fruto e número de lóculos com sementes. Para o teste de emergência, dois experimentos independentes, um para cada espécie, foram instalados em delineamento inteiramente casualizado, com seis métodos de beneficiamento dos frutos para remoção, secagem ou lavagem da mucilagem e quatro repetições com 40 sementes por parcela. Com frutos mais volumosos, com maior acúmulo de massa fresca e maior amplitude biométrica em relação aos de $C$. pubescens, $C$. adamantium apresenta potencial para seleção de materiais promissores para fins de melhoramento. A secagem à sombra por 24 horas das sementes com mucilagem reduz os percentuais de emergência e de plântulas normais, além da velocidade de emergência de plântulas de $C$. adamantium, embora este método seja indiferente para plântulas de C. pubescens. Sob as mesmas condições experimentais, plântulas de $C$. pubescens apresentam maior capacidade de emergência e de plântulas normais, além de maiores frequências diárias de plântulas emersas e redução dos tempos de emergência em relação às plântulas de $C$. adamantium.

Termos para indexação: fermentação, gabiroba, mucilagem, Myrtaceae.

\section{BIOMETRICS OF FRUITS AND SEEDS AND SEEDLING EMERGENCE OF TWO SPECIES OF FRUIT OF THE Campomanesia GENUS}

\begin{abstract}
The species Campomanesia adamantium and Campomanesia pubescens are morphologically similar, they occur in common areas in the Cerrado region, so they are difficult to be separated and identified. The objectives were to analyze biometrics of fruits and seeds of $C$. adamantium and C. pubescens, and the process of emergence of seedlings, for comparisons between species. In November 2007, 50 fruits of each species were measured of the transversal length $(\mathrm{mm})$ and longitudinal $(\mathrm{mm})$ of the fruits and seeds, fresh weight of fruits $(\mathrm{g})$, number of locules per fruit and number of loci seeds. For the emergence testing, two independent experiments, one for each species, were installed in a completely randomized design with six methods of fruit processing for removal, drying or washing the mucilage, and four replicates with 40 seeds per plot. With the fruits of greater volume, with accumulation of fresh and wider biometrics in relation to $C$. pubescens, $C$. adamantium has a potential for selection of promising materials for breeding purposes. Drying in the shade for 24 hours with seed mucilage reduces the percentage of emergence and normal seedlings of C. adamantium, besides the seedlings emergence rate, although this method is indifferent to seedlings of $C$. pubescens. Under the same experimental conditions, seedlings of C. pubescens have a higher emergence capacity and normal seedlings as well as higher daily frequencies of seedlings emerged and reducing the time of emergence in relation to the seedlings of $C$. adamantium.
\end{abstract}

Index terms: fermentation, gabiroba, mucilage, Myrtaceae.

\footnotetext{
${ }^{1}$ (Trabalho 102-10). Recebido em: 22-04-2010. Aceito para publicação em: 19-10-2010. Parte da dissertação de Mestrado do primeiro autor. ${ }^{2}$ MSc., Programa de Pós-graduação em Agronomia, ICIAG/UFU, Uberlândia-MG. E-mail: michele_agro@yahoo.com.br ${ }^{3}$ Dra., Professora do Instituto de Ciências Agrárias, ICIAG/UFU, Uberlândia-MG. E-mail: dgsantana@umuarama.ufu.br ${ }^{4}$ Dr., Professor do Instituto de Ciências Agrárias, ICIAG/UFU, Uberlândia-MG. E-mail: cmsantos@umuarama.ufu.br
} 


\section{INTRODUÇÃO}

Da família, o gênero Campomanesia, subfamília Myrtoidae, ocorre em fitofisionomias de Cerrado, Cerradão e Campo Sujo, com 25 espécies distribuídas do México à Argentina, sendo 15 nativas do Brasil (PEIXOTO et al., 2005). Entre as nativas do gênero Campomanesia, há espécies frutíferas com potencial para cultivo comercial em função das suas características agronômicas desejáveis, como alto rendimento e elevados teores de brix (TEIXEIRA et al., 2005; MELCHIOR et al., 2006). Os frutos são ricos em vitamina e apresentam componentes próprios para fabricação de flavolizantes (PEIXOTO et al., 2005; TEIXEIRA et al., 2005; VALLILO et al., 2006). São consumidos na forma de licores, sorvetes, doces, geleias ou mesmo in natura, além de serem utilizados para fins medicinais (PEIXOTO et al., 2005; VALLILO et al., 2006).

Composto por espécies arborícolas e arbustivas, as arborícolas do gênero Campomanesia medem entre 8 e $15 \mathrm{~m}$, podendo chegar até $25 \mathrm{~m}$, e as arbustivas, entre 0,80 e $1,5 \mathrm{~m}$, ocorrendo normalmente em moitas. Durante o período de inverno, há caducifólia e, na primavera (início do mês de setembro), as plantas rebrotam e florescem abundantemente (ALMEIDA et al., 2000; PEIXOTO et al., 2005). As flores são isoladas, de coloração que varia do branco ao creme, com estigma do tipo seco e sem produção de néctar (ALMEIDA et al., 2000). As espécies do gênero apresentam, na sua maioria, flores perfeitas, porém há casos de autoincompatibilidade (PROENÇA, 1991; ALMEIDA et al., 2000).

As espécies $C$. adamantium Blume e C. pubescens $\mathrm{O}$. Berg são morfologicamente semelhantes, mas diferenciam-se pela presença de pubescência nas folhas jovens e nos frutos de C. pubescens (ARANTES; MONTEIRO, 2002). Na literatura, há poucos relatos sobre $C$. adamantium, por vezes confundida com C. pubescens, e muitas características dos frutos de uma espécie, no caso de C. pubescens, são usadas para caracterizar os frutos de C. adamantium. Contudo, é importante determinar se as diferenças entre as espécies são visíveis ainda em indivíduos jovens e nas características biométricas de frutos e sementes. A biometria é um instrumento importante para detectar variabilidade genética dentro de populações da mesma espécie e as relações com os fatores ambientais, fornecendo subsídios importantes para a diferenciação de espécies do mesmo gênero (CRUZ et al., 2001; GUSMÃO et al., 2006).

Este trabalho teve como objetivo caracterizar, biometricamente, os frutos e sementes, e a emergência

\section{MATERIAL E MÉTODOS}

\section{Locais de coletas}

As coletas foram efetuadas na Reserva Vegetal do Clube Caça e Pesca Itororó (18 55' 23' ' S e $\left.48^{\circ} 17^{\prime} 19^{\prime \prime} \mathrm{W}\right)$, formada por cerrado sensu lato, e a reserva legal da Fazenda Água Limpa da Universidade Federal de Uberlândia (190 05' 57,92" S e $48^{\circ} 20^{\prime} 49,79^{\prime \prime} \mathrm{W}$ ), em área de cerrado sensu stricto, ambas no município de Uberlândia-MG. O clima da região, de acordo com a classificação de Köeppen (1948), é do tipo Aw, caracterizado como chuvoso (clima de savana), megatérmico, com inverno seco e verão úmido.

Há duas estações com marcantes diferenças nos índices pluviométricos, que oscilam anualmente em torno de $1.550 \mathrm{~mm}$ (NIMER; BRANDÃO, 1989).

$\mathrm{O}$ registro do material de consulta de C. adamantium e C. pubescens encontra-se no Herbarium Uberlandensis (HUFU) da Universidade Federal de Uberlândia sob os números $3.624 \mathrm{e}$ 21.376, respectivamente.

\section{Biometria de frutos e sementes}

Em novembro de 2007, 50 frutos de cada espécie foram coletados de 23 e 11 indivíduos de $C$. adamantium e C. pubescens, respectivamente. Para o estudo da biometria, o delineamento experimental foi o inteiramente casualizado, com dois tratamentos correspondentes às espécies, dez repetições de cinco frutos por parcela. Na tomada das medidas, levou-se em consideração o fato de que nem todos os frutos apresentavam formato esférico, alguns eram elipsoides. Assim, mediu-se o comprimento transversal $(\mathrm{mm})$ e longitudinal $(\mathrm{mm})$ dos frutos e das sementes, massa da matéria fresca dos frutos $(\mathrm{g})$, número de lóculos por fruto e número de lóculos com sementes. Com as medidas de comprimento, determinou-se o volume do elipsóide, em $10^{3} \mathrm{~mm}^{3}$, pela expressão: $4 / 3 \pi(a / 2)^{2} \quad(b / 2)$ em que: $a$ é o comprimento longitudinal e $b$ o comprimento transversal.

$\mathrm{Na}$ análise dos dados, aplicou-se o teste " $F$ de Snedecor" a 0,05 de significância, uma vez que as pressuposições quanto à normalidade dos resíduos (teste de Shapiro-Wilk) e homogeneidade entre as variâncias (teste de Levene) foram atendidas para todas as características estudadas. Histogramas foram construídos para o estudo do padrão de distribuição das características biométricas.

\section{Emergência das plântulas}

Frutos de $C$. adamantium e $C$. pubescens foram coletados entre os meses de janeiro de 2007 e novembro de 2008, levados ao Laboratório de 
Sementes Florestais (LASEF) do Instituto de Ciências Agrárias da Universidade Federal de Uberlândia.

Para o teste de emergência, dois experimentos independentes, um para cada espécie ( $C$. adamantium e C. pubescens), foram instalados em delineamento inteiramente casualizado, com seis tratamentos, quatro repetições e 40 sementes por parcela. Os tratamentos consistiram na fermentação da mucilagem das sementes recém-colhidas pela imersão em $20 \mathrm{~mL}$ de água destilada e permanência por 24 (1), 48 (2) e 72 (3) horas em caixa gerbox, à temperatura de $25^{\circ} \mathrm{C}$; lavagem da mucilagem das sementes, em água corrente, por 24 horas (4); secagem das sementes com mucilagem à sombra, à temperatura ambiente, por 24 horas (5), além da semeadura direta (6).

Antes da semeadura, as sementes passaram por rápida lavagem em água destilada e foram colocadas sobre papel-filtro para a retirada do excesso de água. Os teores de água das sementes recém-despolpadas foram determinados em estufa a $70^{\circ} \mathrm{C}$, em sete repetições de 10 sementes para as duas espécies. As sementes foram pesadas diariamente em balança analítica até a massa constante. Os teores de água foram calculados em base seca, segundo a expressão: $(M M F-M M S) * 100 / M M S$, em que: $M M F$ é a massa da matéria fresca da semente e $M M S$ a massa da matéria seca da semente. Para as porcentagens de teores de água das sementes, as médias entre as duas espécies foram comparadas pelo teste $t$ de "Student", a 0,05 de significância.

A semeadura foi realizada a $1 \mathrm{~cm}$ de profundidade, em bandejas multicelulares mantidas em casa de vegetação, com médias das temperaturas máxima e mínima entre $35,98 \pm 4,86{ }^{\circ} \mathrm{C}$ e $20,58 \pm$ $2,02{ }^{\circ} \mathrm{C}$, respectivamente, para $C$. adamantium, e entre $34,65 \pm 4,48{ }^{\circ} \mathrm{C}$ e $20,36 \pm 1{ }^{\circ} \mathrm{C}$, para $C$. pubescens. O substrato utilizado foi a mistura de Plantmax ${ }^{\circledR}$ e Vermicultita ${ }^{\circledR}$ expandida, na mesma proporção $(\mathrm{v} / \mathrm{v})$. As contagens foram realizadas diariamente, e o critério de emergência adotado foi a exposição de qualquer parte da plântula na superfície do substrato.

As características analisadas para cada experimento foram os percentuais de emergência e de plântulas normais, tempos inicial, final e médio de emergência, velocidade de emergência, coeficiente de variação do tempo e sincronia. Expressões originais e autores dessas medidas podem ser consultados em Ranal e Santana (2006).

Para cada experimento de emergência, as pressuposições da ANOVA foram testadas pelos testes de Shapiro-Wilk, para a normalidade dos resíduos e de Bartlett, para homogeneidade entre as variâncias. Quando atendidas, aplicou-se o teste de Tukey para comparações entre os tratamentos e, quando não atendidas, pelo teste de Kruskal-Wallis. Para comparação entre experimentos independentes, foi aplicada a análise conjunta, segundo modelo proposto por Pimentel-Gomes (1990). Em todos os testes estatísticos, foi adotado $\alpha=0,05$ como o valor de significância.

\section{RESULTADOS E DISCUSSÃO}

\section{Biometria de frutos e sementes}

Frutos de C. adamantium apresentaram comprimento transversal e massa da matéria fresca superiores aos frutos de C. pubescens (Tabela 1). Mesmo sendo de origem ancestral comum ao complexo Campomanesia xanthocarpa e ocorrerem nos campos e cerrados do interior do Brasil, a possível hibridação com a espécie Campomanesia xanthocarpa O. Berg in Mart (LANDRUM, 1986), além da autoincompatibilidade parcial (PROENÇA; GIBBS, 1993), podem ser fatores que justificam as diferenças morfológicas entre as espécies.

As duas espécies apresentaram semelhanças em relação ao número médio de lóculos por fruto (5,10 e 4,88 lóculos para C. adamantium e C.pubescens, respectivamente) (Tabela 1). Há autores que correlacionam a variação no número de lóculos por ovário com o tamanho da flor nas espécies de Campomanesia (LANDRUM, 1982). Como as flores de C. adamantium e C. pubescens apresentam grandes semelhanças (LANDRUM, 1986), é esperado que, em termos de número de lóculos, essa semelhança se mantenha.

O número de lóculos que originam sementes foi reduzido em torno de $60 \%$, pois havia aproximadamente 5 lóculos por fruto e apenas 2 sementes. Este fato foi registrado na literatura como uma característica marcante da família Myrtaceae. Segundo Landrum (1982), durante a formação das sementes, a redução no número de óvulos que chegam a formar sementes visa a concentrar as reservas nos óvulos remanescentes. Assim, segundo o mesmo autor, as espécies do gênero investem em uma substância chamada tupertina, encontrada na parede glandular do lóculo e apresenta características organolépticas ruins, a fim de garantir que as sementes sejam preservadas até a dispersão.

Dentre as características estudadas, as de maior variabilidade relativa foram a massa da matéria fresca dos frutos $(C V=41,4 \%)$ e o número de lóculos com sementes $(C V=30,1 \%)$. Os coeficientes de variação foram próximos a $12 \%$ para comprimento transversal, tanto de frutos como de sementes (Tabela 1), enquanto para comprimento longitudinal, a variabilidade dos frutos $(12,61 \%)$ foi superior à de 
sementes $(4,81 \%)$.

A análise da distribuição de frequência revelou que, para C. adamantium, os comprimentos longitudinal e transversal dos frutos concentraram-se, para ambos, entre 15 e $20,99 \mathrm{~mm}$, com frequências acumuladas de 74 e $72 \%$ dos frutos, respectivamente (Figura 1). Os frutos de C. pubescens demonstraram menor amplitude quanto ao comprimento longitudinal, que variou de 13 a 22,99 mm, e transversal, de 13 a 20,99 mm. O comprimento longitudinal dos frutos de $C$. pubescens concentrou-se no intervalo entre 15 e $18,99 \mathrm{~mm}$, com frequência de $68 \%$, e o comprimento transversal, entre 13 e $16,99 \mathrm{~mm}$, correspondente a $72 \%$ dos frutos.

Para as sementes de $C$. adamantium, as maiores frequências concentraram-se entre $5,5 \mathrm{e}$ $6,49 \mathrm{~mm}$ para comprimento longitudinal e entre 2,5 e 3,49 mm para comprimento transversal, com 64 e $56 \%$, respectivamente, e para C. pubescens concentraram-se entre 5,0 e $5,99 \mathrm{~mm}$ para comprimento longitudinal e 2,5 entre e $3,49 \mathrm{~mm}$ para comprimento transversal, com frequências de $74 \mathrm{e}$ 94\%, respectivamente (Figura 2).

Assim como observado para o comprimento de frutos e sementes, frutos de C. adamantium também apresentaram as maiores amplitudes para a massa da matéria fresca e o volume (Figura 3). A massa da matéria fresca e o volume dos frutos de $C$. pubescens apresentaram amplitudes entre 1 e 5,99 g e 1 e $5,9910^{3} \mathrm{~mm}^{3}$, respectivamente, indicando que os frutos de $C$. adamantium apresentaram dimensões maiores que frutos de $C$. pubescens.

Mais da metade (54\%) dos frutos de $C$. adamantium apresentaram 5 lóculos e, do total, quase a metade $(48 \%)$ apresentaram apenas uma semente (Figura 4). De C. pubescens o número de lóculos por fruto também apresentou maior frequência com 5 lóculos, porém cerca de $38 \%$ do total apresentaram 2 sementes.

Em estudos realizados com frutos de $C$. adamantium e C. pubescens, os registros biométricos foram sempre muito próximos aos encontrados neste estudo. Landrum (1986) encontrou ovários de $C$. adamantium com 5 e 9 lóculos; comprimento transversal dos frutos entre 15 e $20 \mathrm{~mm}$; frutos com 1 a 4 sementes, com comprimento transversal de 5 a $7 \mathrm{~mm}$. Outros autores relatam o comprimento longitudinal dos frutos em média de $18 \mathrm{~mm}$ (ARANTES; MONTEIRO, 2002) e variável entre 14 e 22 $\mathrm{mm}$ (MELCHIOR et al., 2006). Segundo Melchior et al. (2006), o número de sementes, em média, encontrados na literatura, foi de 3,10 e variou entre 1,20 e 4,05. Neste estudo, o número de sementes foi menor $(2,02)$, porém com intervalo maior (entre $1 \mathrm{e}$
6). Ainda, há registros na literatura de que frutos de C. adamantium pesam, em média, 2,30 g (VALLILO et al., 2006), com máximo e mínimo entre 5,59 e 1,36 g, respectivamente (MELCHIOR et al., 2006),

Para C. pubescens, há menos registros na literatura sobre frutos e sementes. Os frutos apresentam ovário com 4 a 7 lóculos; comprimento transversal entre 10 e 20 mm e 3 a 5 sementes com comprimento transversal de 5 a $7 \mathrm{~mm}$ (LANDRUM, 1986). Segundo Almeida et al. (1998), esta mesma espécie apresenta ovário com 5 a 8 lóculos; comprimento transversal entre 10 e $12 \mathrm{~mm}$, com 1 a 9 sementes, as quais medem de comprimento transversal $5 \mathrm{~mm}$. Para Arantes e Monteiro (2002), o comprimento longitudinal está entre 17 e $20 \mathrm{~mm}$, e segundo Morais e Lombardi (2006), os frutos têm entre 6 e 8 lóculos.

\section{Processo de emergência de plântulas}

Os teores de água das sementes de C. adamantium e C. pubescens foram, em média, de 54,98 $\pm 4,20 \%$ e $61,6 \pm 2,67 \%$, respectivamente, e não variaram significativamente entre as espécies. Perioto e Perez (2007a) encontraram para as sementes de frutos frescos de C. pubescens teores de água de aproximadamente $50 \%$, e este teor foi obtido de sementes não fermentadas. Entretanto, segundo Melchior et al. (2006), as sementes de frutos frescos de $C$. adamantium apresentam $30 \%$ de teor de água, porém este teor foi obtido de sementes após a fermentação da mucilagem. As diferenças entre os teores de água encontrados e os registrados na literatura devem-se ao cálculo em base seca determinando para as espécies, em contraste com a literatura, determinado na base úmida.

Uma característica do gênero Campomanesia observada foi a alta capacidade de germinação das sementes e, consequentemente, da emergência das plântulas. Segundo Perioto e Perez (2007b), a maior porcentagem de emergência de plântulas de $C$. pubescens, foi de 96\%. Melchior et al. (2006) obtiveram índices de germinação de C. adamantium, no mínimo, $74 \%$ quando as sementes de frutos recém-colhidos foram semeadas, apresentando alta velocidade quando nas mesmas condições.

Os percentuais de emergência de plântulas normais e a velocidade de emergência das plântulas de C. adamantium foram reduzidos quando as sementes secaram a sombra por 24 horas, mas este mesmo método foi indiferente para plântulas de C. pubescens (Tabela 2). A fermentação dos frutos por 24; 48 ou 72 horas não aumentou a capacidade de emergência das plântulas, nem mesmo das plântulas normais das duas espécies, em relação à semeadura direta.

A mucilagem das sementes de ambas as espé- 
cies de Campomanesia não apresentaram inibidores de germinação, permitindo emergência de mais de $85 \%$ das plântulas. Assim, a necessidade da retirada da mucilagem das sementes por meio da fermentação, para alcançar altas taxas de germinação, não foi observada neste estudo. Segundo Carmona et al. (1994), sementes de Campomanesia apresentam mucilagem que inibe a germinação e o desenvolvimento inicial de plântulas, pois esta mucilagem favorece o desenvolvimento de microrganismos.

Sob mesmas condições, plântulas de $C$. pubescens apresentaram maior capacidade de emergência (entre 85 e 89,37\%), e de plântulas normais (entre 79,37 e 88,12\%), além de níveis superiores de frequência diária de plântulas emersas, entre 1,83 e 2,30 plântulas por dia em relação às plântulas de $C$. adamantium (Tabela 2).

Os tratamentos não afetaram os tempos inicial e final de emergência das plântulas das duas espécies nem mesmo a sincronia, mas a secagem por 24 horas aumentou o tempo médio de emergência das plântulas de C. adamantium (Tabela 3). De maneira geral, plântulas de C. pubescens iniciaram e terminaram o processo de emergência das plântulas mais rápido em relação às plântulas de $C$. adamantium, e também com os menores tempos médios, mas foram semelhantes quanto à sincronia do processo.

TABELA 1- Medidas biométricas (média \pm desvio-padrão) de frutos e sementes de Campomanesia adamantium Blume e Campomanesia pubescens O. Berg.

\begin{tabular}{|c|c|c|c|c|c|c|}
\hline & \multirow{2}{*}{ Biometria } & \multicolumn{2}{|c|}{ Espécies $^{1}$} & \multicolumn{3}{|c|}{ Estatísticas $^{2}$} \\
\hline & & C. adamantium & C. pubescens & $C V(\%)$ & $F$ & $W$ \\
\hline \multirow{6}{*}{ 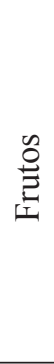 } & Comprimento longitudinal (mm) & $19,39 \pm 3,31 \mathrm{a}$ & $17,30 \pm 2,00 \mathrm{a}$ & 12,61 & 3,49 & 0,92 \\
\hline & Comprimento transversal (mm) & $18,30 \pm 2,92 \mathrm{a}$ & $16,34 \pm 1,80 \mathrm{~b}$ & 11,70 & 2,76 & 0,93 \\
\hline & Massa da matéria fresca (g) & $4,15 \pm 2,08 \mathrm{a}$ & $2,63 \pm 0,88 \mathrm{~b}$ & 41,39 & 5,32 & 0,89 \\
\hline & Volume dos frutos $\left(10^{3} \mathrm{~mm}^{3}\right)$ & $3,90 \pm 2,06 \mathrm{a}$ & $2,67 \pm 0,92 \mathrm{a}$ & 19,05 & 3,43 & 0,91 \\
\hline & № de lóculos por fruto & $5,10 \pm 0,76 \mathrm{a}$ & $4,88 \pm 0,93 \mathrm{a}$ & 7,37 & 0,44 & 0,98 \\
\hline & № de lóculos com sementes & $2,02 \pm 1,22 \mathrm{a}$ & $2,18 \pm 1,13 \mathrm{a}$ & 30,10 & 7,16 & 0,92 \\
\hline \multirow{2}{*}{ 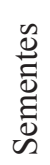 } & Comprimento longitudinal (mm) & $6,00 \pm 0,48 \mathrm{a}$ & $5,26 \pm 0,37 \mathrm{~b}$ & 4,81 & 3,77 & 0,98 \\
\hline & Comprimento transversal (mm) & $2,85 \pm 0,66 \mathrm{a}$ & $2,92 \pm 0,27 \mathrm{a}$ & 11,69 & $\mathbf{5 , 5 0}$ & 0,96 \\
\hline
\end{tabular}

${ }^{1}$ Médias seguidas por letras distintas na linha, para cada característica analisada, diferem entre si, pelo teste $F$, a 0,05 de significância; ${ }^{2} F, W$ : estatísticas do testes de Levene e de Shapiro-Wilk; valores em negrito indicam homogeneidade das variâncias e normalidade dos resíduos, respectivamente. 
TABELA 2 - Capacidade de emergência, de plântulas normais e velocidade de emergência (VE) de plântulas de Campomanesia adamantium Blume e Campomanesia pubescens O. Berg. sob diferentes tratamentos, para a retirada da mucilagem da semente.

\begin{tabular}{|c|c|c|c|c|c|c|}
\hline \multirow[b]{2}{*}{ Tratamento $^{1}$} & ${ }^{2} \mathrm{Ca}$ & $C p$ & $\mathrm{Ca}$ & $C p$ & $\mathrm{Ca}$ & $C p$ \\
\hline & \multicolumn{2}{|c|}{ Emergência (\%) } & \multicolumn{2}{|c|}{ Plântulas normais (\%) } & \multicolumn{2}{|c|}{$V E\left(\right.$ pl.dia $\left.^{-1}\right)$} \\
\hline Fermentação 24 h & $80,00 \mathrm{abA}$ & $89,37 \mathrm{aA}$ & $64,37 \mathrm{ab}$ & $81,87 \mathrm{a}$ & $1,678 \mathrm{abB}$ & $2,247 \mathrm{aA}$ \\
\hline Fermentação 48 h & $78,75 \mathrm{abA}$ & $89,37 \mathrm{aA}$ & $74,37 \mathrm{a}$ & 88,12 a & $1,652 \mathrm{abB}$ & $2,165 \mathrm{aA}$ \\
\hline Fermentação 72 h & 85,00 a $\mathrm{A}$ & $85,62 \mathrm{aA}$ & $66,87 \mathrm{ab}$ & $79,37 \mathrm{a}$ & $1,743 \mathrm{abB}$ & $1,983 \mathrm{aA}$ \\
\hline Lavagem em água & $75,62 \mathrm{abB}$ & $89,37 \mathrm{aA}$ & $61,87 \mathrm{ab}$ & $81,25 \mathrm{a}$ & $1,556 \mathrm{abB}$ & $2,296 \mathrm{aA}$ \\
\hline Secagem 24 horas & $61,25 \mathrm{bB}$ & $85,00 \mathrm{aA}$ & $43,12 \mathrm{~b}$ & $81,25 \mathrm{a}$ & $1,148 \mathrm{bB}$ & $1,829 \mathrm{aA}$ \\
\hline Semeadura direta & $90,00 \mathrm{aA}$ & $86,87 \mathrm{aA}$ & $78,75 \mathrm{a}$ & $81,12 \mathrm{a}$ & $2,064 \mathrm{aB}$ & $2,206 \mathrm{aA}$ \\
\hline Média & 78,44 & 87,57 & $64,89 \mathrm{~B}$ & $82,29 \mathrm{~A}$ & 1,640 & 2,121 \\
\hline
\end{tabular}

${ }^{1}$ Médias seguidas por letras distintas, minúsculas na coluna e maiúsculas na linha, diferem entre si, pelos testes de Tukey e Dunn, ambos a 0,05 de significância; ${ }^{2} \mathrm{Ca}$ : Campomanesia adamantium e Cp: Campomanesia pubescens.

TABELA 3 - Medidas de tempo inicial $\left(t_{\mathrm{o}}\right)$, final $\left(t_{\mathrm{f}}\right)$ e médio $(t)$ e sincronia $(Z)$ de emergência de plântulas de Campomanesia adamantium Blume e Campomanesia pubescens O. Berg. sob diferentes tratamentos, para a retirada da mucilagem da semente.

\begin{tabular}{|c|c|c|c|c|c|c|c|c|}
\hline \multirow[b]{2}{*}{ Tratamento $^{1}$} & ${ }^{2} \mathrm{Ca}$ & $C p$ & $\mathrm{Ca}$ & $C p$ & $\mathrm{Ca}$ & $C p$ & $\mathrm{Ca}$ & $C p$ \\
\hline & \multicolumn{2}{|c|}{$t_{0}(\mathrm{dia})$} & \multicolumn{2}{|c|}{$t_{\mathrm{f}}(\mathrm{dia})$} & \multicolumn{2}{|c|}{$\bar{t}(\mathrm{dia})$} & \multicolumn{2}{|c|}{$Z$} \\
\hline Fermentação 24 h & $15,50 \mathrm{aB}$ & $10,75 \mathrm{aA}$ & $35,25 \mathrm{a}$ & $31,75 \mathrm{a}$ & $20,25 \mathrm{ab}$ & 17,19 a & $0,114 \mathrm{a}$ & $0,098 \mathrm{a}$ \\
\hline Fermentação 48 h & $16,50 \mathrm{aB}$ & $10,75 \mathrm{aA}$ & $34,50 \mathrm{a}$ & $36,25 \mathrm{a}$ & $20,65 \mathrm{ab}$ & $17,64 \mathrm{a}$ & $0,107 \mathrm{a}$ & $0,087 \mathrm{a}$ \\
\hline ação 72 h & $14,75 \mathrm{aB}$ & $11,25 \mathrm{aA}$ & $39,00 \mathrm{a}$ & $32,00 \mathrm{a}$ & $20,63 \mathrm{ab}$ & $18,29 \mathrm{a}$ & $0,126 \mathrm{a}$ & $0,082 \mathrm{a}$ \\
\hline Lavagem em água & $15,25 \mathrm{aB}$ & $11,00 \mathrm{aA}$ & $37,50 \mathrm{a}$ & $27,25 \mathrm{a}$ & $21,08 \mathrm{ab}$ & $16,44 \mathrm{a}$ & $0,102 \mathrm{a}$ & $0,128 \mathrm{a}$ \\
\hline horas & $14,00 \mathrm{aA}$ & $13,25 \mathrm{aA}$ & $48,00 \mathrm{a}$ & $34,50 \mathrm{a}$ & $23,60 \mathrm{~b}$ & 19,36 a & $0,084 \mathrm{a}$ & $0,112 \mathrm{a}$ \\
\hline Semeadura direta & $14,00 \mathrm{aB}$ & $11,00 \mathrm{aA}$ & $32,50 \mathrm{a}$ & $32,00 \mathrm{a}$ & $18,08 \mathrm{a}$ & $16,63 \mathrm{a}$ & $0,123 \mathrm{a}$ & $0,120 \mathrm{a}$ \\
\hline Média & 15,00 & 14,17 & $37,29 \mathrm{~B}$ & $32,79 \mathrm{~A}$ & $20,71 \mathrm{~B}$ & $17,59 \mathrm{~A}$ & $0,109 \mathrm{~A}$ & $0,105 \mathrm{~A}$ \\
\hline
\end{tabular}

${ }^{1}$ Médias seguidas por letras distintas, minúsculas na coluna e maiúsculas na linha, diferem entre si, pelos testes de Tukey e Dunn, ambos a 0,05 de significância; ${ }^{2} \mathrm{Ca}$ : Campomanesia adamantium e $C p$ : Campomanesia pubescens. 
Frutos

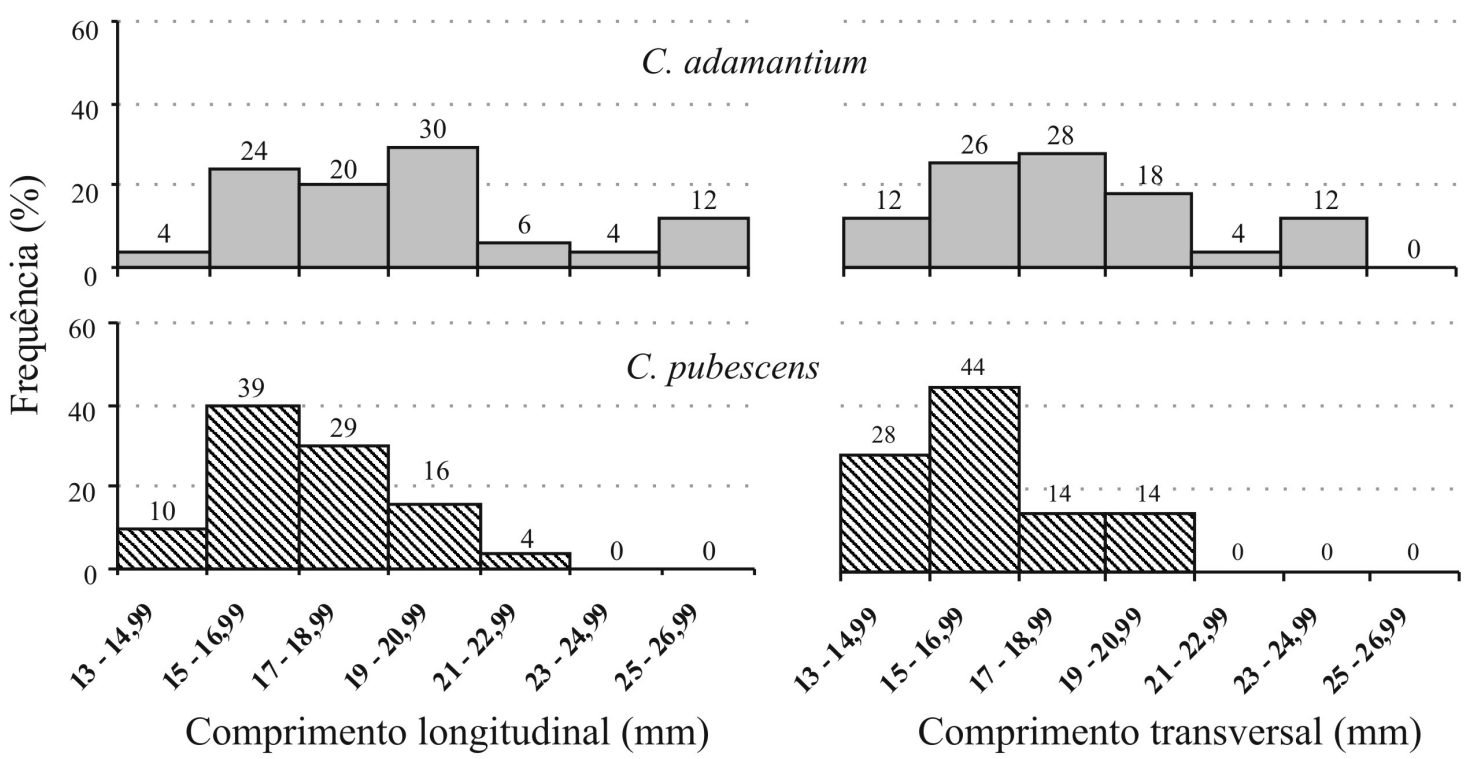

FIGURA 1 - Frequência percentual do comprimento longitudinal (mm) e transversal (mm) de frutos de Campomanesia adamantium Blume e Campomanesia pubescens O. Berg.

\section{Sementes}

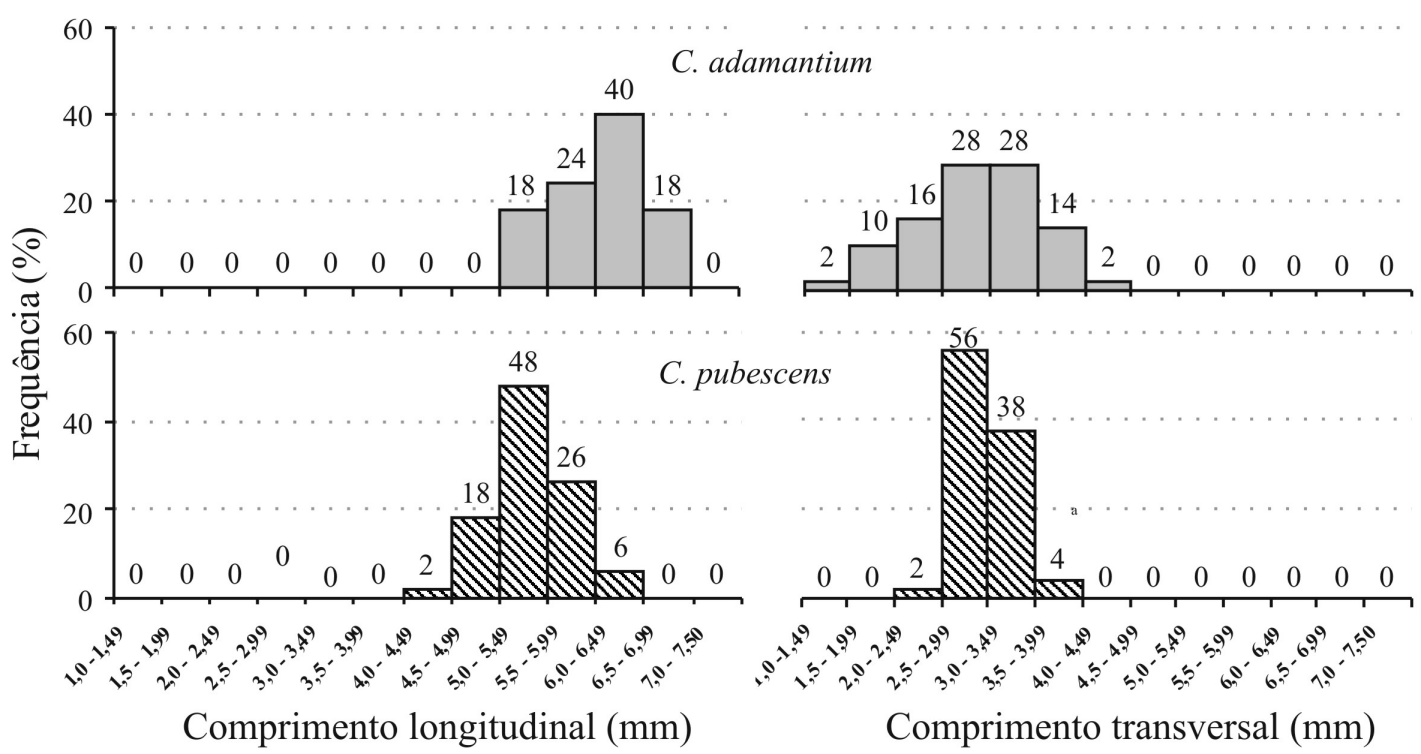

FIGURA 2 - Frequência percentual do comprimento longitudinal ( $\mathrm{mm}$ ) e transversal (mm) de sementes de Campomanesia adamantium Blume e Campomanesia pubescens O. Berg. 
Massa e volume dos frutos

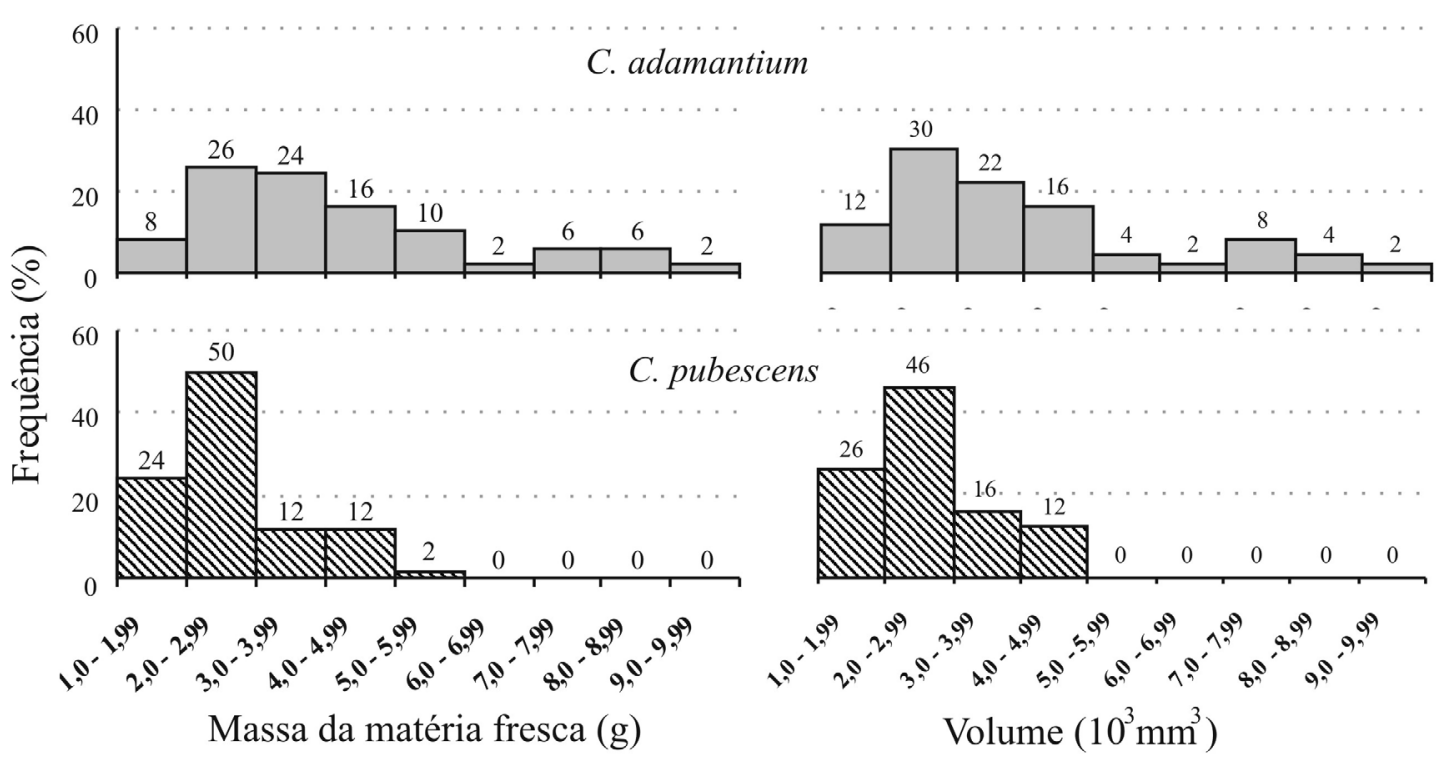

FIGURA 3 - Frequência percentual da massa da matéria fresca $(\mathrm{g})$ e volume $\left(10^{3} \mathrm{~mm}^{3}\right)$ dos frutos de Campomanesia adamantium Blume e Campomanesia pubescens O. Berg.

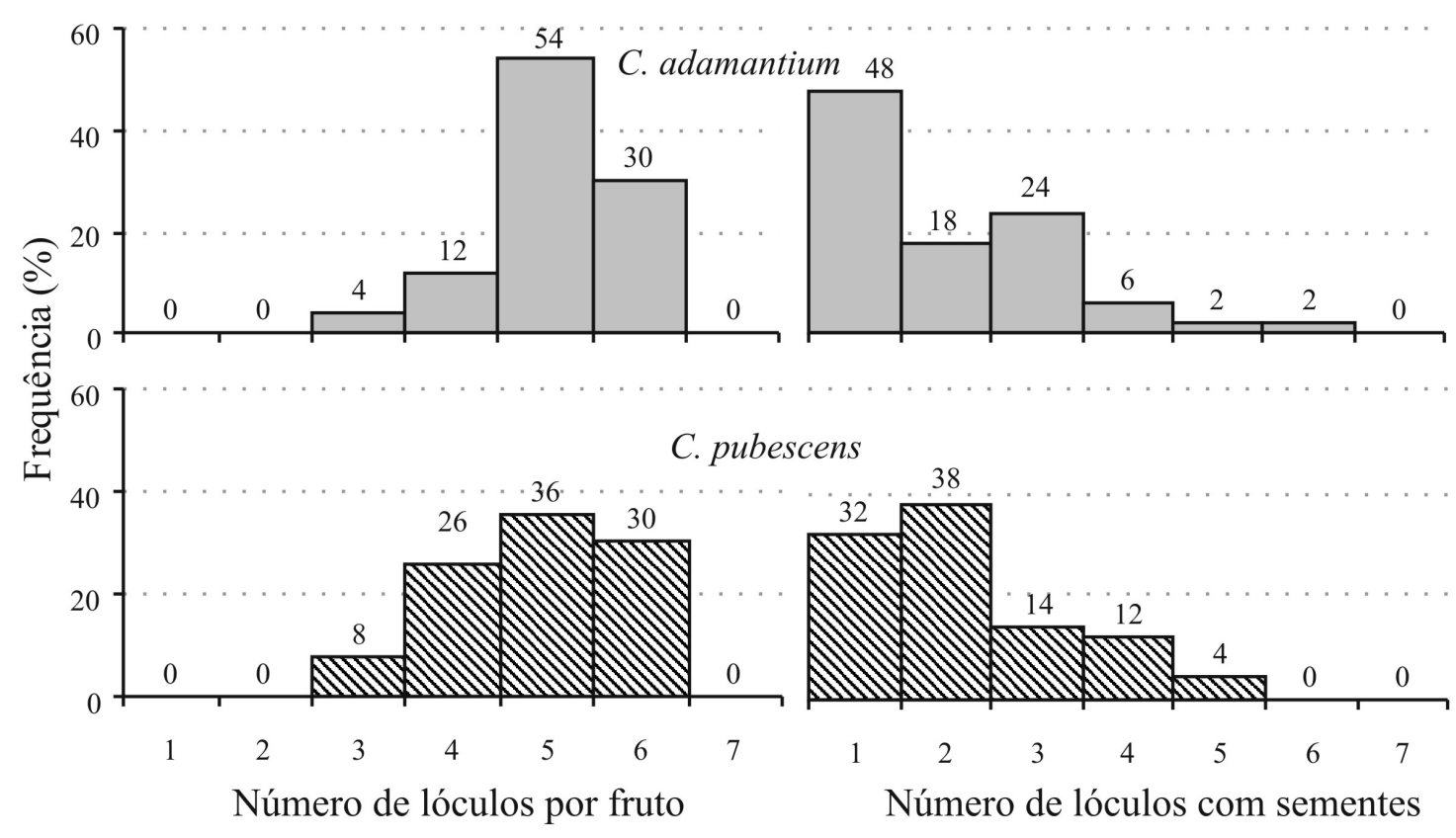

FIGURA 4 - Frequência percentual do número de lóculos por fruto e lóculos com sementes de Campomanesia adamantium Blume e Campomanesia pubescens O. Berg. 


\section{CONCLUSÃO}

1-Com frutos de maior volume, com maior acúmulo de massa fresca e maior amplitude biométrica em relação aos de Campomanesia pubescens, Campomanesia adamantium apresenta potencial para seleção de materiais promissores para fins de melhoramento.

2-A secagem à sombra por 24 horas, de sementes com mucilagem, reduz os percentuais de emergência e de plântulas normais, além da velocidade de emergência das plântulas de Campomanesia adamantium, embora a secagem seja indiferente para plântulas de Campomanesia pubescens.

3-Sob as mesmas condições experimentais, plântulas de Campomanesia pubescens apresentam maior capacidade de emergência e de plântulas normais, além de maiores frequências diárias de plântulas emergidas e redução dos tempos de emergência em relação às plântulas de Campomanesia adamantium.

\section{AGRADECIMENTOS}

Os autores agradecem à Coordenação de Aperfeiçoamento de Pessoal de Nível Superior (CAPES), pela concessão da bolsa de Mestrado da primeira autora.

\section{REFERÊNCIAS}

ALMEIDA, M.J.F.; NAVES, R.V.; XIMENES, P.A. Influência das abelhas (Apis mellifera) na polinização da gabiroba (Campomanesia spp.). Pesquisa Agropecuária Tropical, Goiânia, v.30, n.2, p.25-28, 2000.

ALMEIDA, S.P.; PROENÇA, C.E.B.; SANO, S.M.; RIBEIRO, J.F. Cerrado: espécies vegetais úteis. Planaltina: Embrapa, 1998. 464p.

ARANTES, A.A.; MONTEIRO, R. A família Myrtaceae na Estação Ecológica do Panga, Uberlândia, Minas Gerais, Brasil. Lundiana, Belo Horizonte, v.3, n.2, p.111-127, 2002.

CARMONA, R.; REZENDE, L.P.; PARENTE, T.V. Extração química de sementes de gabiroba (Campomanesia adamantium Camb.). Revista Brasileira de Sementes, Pelotas, v.16, n.1, p.31-33, 1994.
CRUZ, E.D.; MARTINS, F. de O.; CARVALHO, J.E.U. Biometria de frutos e sementes e germinação de jatobá-curuba (Hymenaea intermedia Ducke, Leguminosae Caesalpinioideae). Revista Brasileira de Botânica, São Paulo, v.24, n.2, p.161-165, 2001

GUSMÃO, E.; VIEIRA, F.A.; FONSECA JÚNIOR, E.M. Biometria de frutos e endocarpos de murici (Byrsonima verbascifolia Rich. ex A. Juss.) Revista Cerne, Lavras, v.12, n.1, p. 84-91, 2006.

KÖEPPEN, W. Climatología: com um estúdio de los climas de la tierra. México: Fondo de Cultura Econômica, 1948. 479p.

LANDRUM, L.R. Campomanesia, Pimenta, Blepharocalyx, Legrandia, Acca, Myrrhinium, and Luma (Myrtaceae). Flora Neotropica, New York, n.45, p.1-178, 1986. LANDRUM, L.R. The development of the fruits and seeds of Campomanesia (Myrtaceae). Brittonia, New York, v.34, n.2, p.220-224, 1982.

MELCHIOR, S.J.; CUSTÓDIO, C.C.; MARQUES, T.A.; MACHADO NETO, N.B. Colheita e armazenamento de sementes de gabiroba (Campomanesia adamantium Camb. - Myrtaceae) e implicações na germinação. Revista Brasileira de Sementes, Brasília, v. 28, n. 3, p.141-150, 2006.

MORAIS, P.O.; LOMBARDI, J.A. A família Myrtaceae na reserva particular do patrimônio natural da Serra do Caraça. Catas Altas, Minas Gerais, Brasil. Lundiana, Belo Horizonte, v.7, n.1, p.3-32, 2006.

NIMER, E.; BRANDÃO, A.M.P.M. Balanço hídrico e clima da região dos cerrados. Rio de Janeiro: Fundação IBGE, 1989. 166 p.

PEIXOTO, N.; SILVA, E.; TEIXEIRA, F.G.; MOREIRA, F.M. Avaliação de crescimento inicial de populações de gabiroba em Ipameri. In: SEMINÁRIO DE INICIAÇÃO CIENTÍFICA, 1.,JORNADA DE PESQUISA E PÓS-GRADUAÇÃO, 3., 2005, Anápolis. Anais... Anápolis, 2005.

PERIOTO, F.; PEREZ, S.C.J.G.A. Aspectos básicos de sementes de gabiroba Campomanesia pubescens (Myrtaceae) In: CONGRESSO NACIONAL DE BOTÂNICA - CONSERVAÇÃO DA FLORA BRASILEIRA, 58., 2007, São Paulo. Anais... São Paulo: SBB, 2007a.

PERIOTO, F.; PEREZ, S.C.J.G.A. Germinação de sementes, emergência e crescimento de plântulas de 
Campomanesia pubescens - Myrtaceae In: CONGRESSO NACIONAL DE BOTÂNICA - CONSERVAÇÃO DA FLORA BRASILEIRA, 58., 2007, São Paulo. Anais... São Paulo: SBB, 2007b.

PIMENTEL-GOMES, F. Curso de estatística experimental. 13.ed. Piracicaba: Nobel, 1990. 468p.

PROENÇA, C.E.B.; GIBBS, P.E. Reproductive biology of eight sympatric Myrtaceae from Central Brazil. New Phytologist, Cambridge, v.126, n.2, p.343-344, 1993.

PROENÇA, C. E. The reproductive biology and taxonomy of the Myrtaceae of the Distrito Federal. St. Andrew: University of St. Andrews, 1991. 28p.
RANAL, M.A; SANTANA, D.G. How and why to measure the germination process? Revista Brasileira de Botânica, São Paulo, v.29, n.1, p.1-11, 2006.

TEIXEIRA, F.G.; SILVA, E.S.; MOREIRA, F.M.; PEIXOTO, N. Avaliação de crescimento de plantas de Campomanesia pubescens O. Berg em diferentes substratos. In: SEMINÁRIO DE INICIAÇÃO CIENTÍFICA, 3., JORNADA DE PESQUISA E PÓSGRADUAÇÃO, 1., 2005, Anápolis. Anais... 2005.

VALLILO, M.I.; LAMARDO, L.C.A.; GABERLOTTI, M.L.; OLIVEIRA, E.; MORENO, P.R.H. Composição química dos frutos de Campomanesia adamantium (Cambessédes) O. Berg. Ciência Tecnologia de Alimentos, Campinas, v.4, n.26, p. 805-810, 2006. 